O Open Access Full Text Article

ORIGINALRESEARCH

\title{
Investigating Stress and Sources of Stress Among Female Health Profession Students in a Saudi
} University

\author{
Mona Faisal Al-Qahtani (D) \\ Ali Saad R Alsubaie \\ Department of Public Health, College of \\ Public Health, Imam Abdulrahman Bin \\ Faisal University, Dammam, Kingdom of \\ Saudi Arabia
}

This article was published in the following Dove Press journal: Journal of Multidisciplinary Healthcare

Background: Health profession students experience tremendous levels of stress throughout their education. A high level of stress may have a negative effect on the cognitive functioning and learning of students.

Objective: The study sought to determine the levels and main sources of stress and its possible correlation with academic performance in the preclinical female health profession.

Methods: The cross-sectional design involved the use of self-administered questionnaires. Data were collected from 260 students in health profession programmes in Saudi Arabia. The Medical Student Stressor Questionnaire (MSSQ) was used to collect the data from all second-, third-, and fourth-year undergraduate students.

Results: A high level of stress was observed in $42.7 \%$ of the students, and a moderate stress level was observed in $41.5 \%$ of the students. The major source of stress experienced by students was related to the academic domain (mean= $2.7 \pm 0.73$ ), followed by the group activity domain (mean $=2.1 \pm 0.91 ; p<0.05$ ). Second-year and third-year students were significantly less likely to show high stress levels compared with fourth-year students $(\mathrm{AOR}=0.3 ; 95 \% \mathrm{CI}: 0.1-0.8 ; p \leq 0.030$ and $\mathrm{AOR}=0.4 ; 95 \% \mathrm{CI}: 0.1-0.5 ; p \leq 0.001$, respectively). High stress levels were not found to be associated with students' age and academic performance.

Conclusion: Half of the students experienced high and severe levels of stress. Academic and group activity domains were perceived as the major stressors. The year of study was the only significant factor associated with stress levels. Stress among female health profession students should be acknowledged, and efforts should be made to alleviate it. Students should be guided to reduce their stress levels, as this can enhance their quality of life and study experience.

Keywords: academic performance, female, health profession, students, stress, university

\section{Introduction}

Stress is not only a reaction to an environmental stimulus but also a process through which individuals feel and contend with the challenges and threats in their environments. ${ }^{1}$ Stressors are personal and environmental circumstances that generate stress. ${ }^{2}$ Stress thus involves 'emotional disturbances or changes caused by stressors'. 3

Experiences of stress among students are considered a major problem in higher education. Indeed, the literature emphasizes the adverse impact of stress on students. For example, failure to cope with stress might have an adverse influence on
Correspondence: Mona Faisal Al-Qahtan Department of Public Health, College of Public Health, Imam Abdulrahman Bin Faisal University, PO Box 2435, Dammam 3 I44I, Kingdom of Saudi Arabia Tel +966504981410

Email malqahtani@iau.edu.sa 
students' mental and physical well-being ${ }^{4,5}$ and could become a burden. ${ }^{6}$ Yusoff et $\mathrm{al}^{7}$ conducted a study to determine the impact of medical education on the psychological health of students. The results showed that the main health problems were anxiety $(41.1-56.7 \%)$, followed by depression (12-30\%) and stress (11.9-19.9\%). The learning environment at medical school is considered to be a particularly stressful environment.

According to Linn and Zeppa, ${ }^{8}$ some stress is required for learning in medical school training. However, analogous stressors may be perceived differently by different medical students according to their individual characteristics, cultural backgrounds, coping strategies, and experiences. ${ }^{3,9}$ The main sources of stressors for medical students have been found to be related to academic, intrapersonal, interpersonal, teaching, and learning activities as well as social drive and desire. ${ }^{4,9}$

Findings of previous studies showed that female students in medical education are prone to suffer from abuse, sexual harassment, burnout, stress, depression, anxiety related to academic demand, and medical competency, and they worry more often than their male counterparts about their academic performance. ${ }^{10-15}$ Other studies have indicated that female students tend to have more stress due to their willingness to put more effort into their studies to achieve their expectations. ${ }^{15,16}$ The major stressors among female medical students are social, teaching and learning, interpersonal, and group activity-related stressors. ${ }^{17}$ Previous findings also confirmed the association of excessive stress levels with lowered academic achievement in female medical students. ${ }^{17}$

High frequencies of stress were reported in medical students in different regions of the world, including Egypt $(59.9 \%)^{18}$ and Pakistan (60\%). ${ }^{19}$ Within Saudi Arabia, previous studies reported the prevalence of stress among medical students as $63 \%$ at King Saud University, ${ }^{12} 53 \%$ at King Faisal University, ${ }^{20} 71.1 \%$ at the University of Dammam, ${ }^{21} 53 \%$ in King Saud Bin Abdulaziz University for Health Sciences, ${ }^{22}$ and $82 \%$ in the Faculty of Medicine in the Kingdom of Saudi Arabia. ${ }^{15}$ This paper explores the levels and main sources of stress experienced by preclinical undergraduate female students of health profession programs at a governmental university in the Kingdom of Saudi Arabia. It also examines the possible association between academic performance as measured by student self-reported grade point average (GPA) and levels of stress. The findings of this study will contribute to the international medical educational literature on the effect of stress on students' academic performance.

\section{Methodology \\ Study Design}

A cross-sectional design using stratified random sampling (based on profession programs) was employed to collect the research data. The study was conducted between March and April of the academic year 2019-2020. This time period was appropriate to appraise the natural stress levels.

\section{Study Setting}

This study was conducted in the female section of a government university in the Kingdom of Saudi Arabia (KSA).

\section{Study Population and Sample Size}

The population was comprised of female undergraduate students studying at allied health profession programs in a governmental university (KSA) during their preclinical years. The medical allied sciences curriculum for the health profession in Saudi Arabia takes five years to complete. The first study year for health profession students is the foundation year, in which they study general courses. In the next three years, students study health science courses, and in the fifth year they move to clinical practice in hospitals. The sample includes all second-, third-, and fourth-year female undergraduate students studying in six health profession programs: Cardiac Technology, Physical Technology, Respiratory Care, Clinical Nutrition, Health Information Management \& Technology, and Public Health. The inclusion criteria were female undergraduate students studying in allied health profession programs at the target governmental university during their preclinical years. The exclusion criteria were students who were absent and did not attend college classes during the data collection period and those who were unwilling to take part in the study.

\section{Instrument}

The Medical Student Stressor Questionnaire (MSSQ) ${ }^{3}$ (in the English language) was adopted to explore the levels and sources of stress perceived by the students. The construct validity, construct reliability, and internal consistency of the MSSQ have been examined in a number of studies (eg, Yusoff ${ }^{9,23}$ ), which showed that it has good psychometric values (the Cronbach's alpha value of the MSSQ was 0.92, and the Cronbach's alpha values of the 
six domains were more than 0.70 ) and is a valid and reliable measure for identifying stressors. The MSSQ contains 20 items that cover six subscales: Academic-Related Stressors (ARS), Intrapersonal and Interpersonal Related Stressors (IRS), Teaching and Learning Stressors (TLRS), Social-Related Stressors (SRS), Drive- and Desire-Related Stressors (DRS), and Group Activity-Related Stressors (GARS). Items in the MSSQ represent 20 events that might be sources of stress (eg, "lack of time to review what have been learnt", "heavy workload"). Students were asked to rate each event based on problems they faced over the past four weeks by selecting from five responses. The responses were measured on a five-point Likert scale: " $0=$ causing no stress", " $1=$ causing mild stress", " $2=$ causing moderate stress", " $3=$ causing high stress", or " $4=$ causing severe stress". The mean score for the MSSQ is calculated by summing all the item scores and dividing the sum by the total number of items. The mean score for individual subscales is calculated by summing the item scores in that particular subscale and dividing the sum by the total number of items in that subscale. The mean subscale score was classified as "causing nil to mild stress" if the mean score lies between 0.00 and 1.00, "causing mild to moderate stress" if it lies between 1.01 and 2.00, "causing moderate to high stress" if it lies between 2.01 and 3.00, and "causing high to sever stress" if it lies between 3.01 and $4.00 .{ }^{3}$ Cronbach's alpha coefficient was calculated for the overall questionnaire and for each of the six subscales to measure the internal consistency of the questionnaire. Cronbach's alpha values between 0.7 and 0.9 were considered to indicate high internal consistency, and those between 0.6 and 0.7 were considered to indicate satisfactory internal consistency. ${ }^{24}$

In addition, sociodemographic information, such as age, year of study, professional field of study, and grade point average, were included in the questionnaire.

A pilot study was performed to test the feasibility and applicability of the MSSQ. Five students from another health profession program at the target governmental university were surveyed. It took them about 10 to 15 minutes to complete the questionnaire. The results showed that the questionnaire was clear, and there was no ambiguous wording. Their responses were not included in the main data.

\section{Data Analysis}

The Statistical Package for Social Sciences (SPSS, IBM, Chicago, Illinois, USA) version 20 was used for data analysis. Categorical data are presented as frequencies and percentages, while continuous data are presented as means and standard deviations. One-way ANOVA tests were used to observe the mean difference in MSSQ domains by students' year of study. A binary logistic regression analysis was carried out to access the association between stress levels and students' academic performance and year of study, adjusting for the students' age. For the binary regression analysis, stress level was dichotomized into low stress [if mean $=0$ to $<2$ ] and high stress level [if mean $=2-4$ ] based on the scale cutoff. A P-value of less than 0.05 was considered significant. For the binary regression analysis, stress was dichotomized into low and high stress levels.

\section{Ethical Considerations}

Ethical approval to perform the study was obtained from the institutional review board (IRB-2019-03-189) of Imam Abdulrahman Bin Faisal University in the KSA. All participants provided written informed consent.

\section{Results}

As shown in Table 1, a total of 260 (71\%) health profession students participated in this study. All students were Saudi nationals, and their mean age was $20.4(\mathrm{SD}=0.97)$ with a range of 19-22 years. Nearly $40 \%$ of the respondents were third-year students, almost one-third were fourth-year students, and only 30\% were second-year students. Moderate levels of stress were observed in $41.5 \%$ of the students, while high and severe stress levels were observed in $42.7 \%$ and $8.1 \%$ of the students, respectively. Of the respondents, $84(32.3 \%)$ had a grade point average (GPA) indicating excellent academic performance, 144 (55.4\%) had a very good GPA, 21 (8.1\%) had a good GPA, and $11(4.3 \%)$ had an average GPA.

Table 2 shows that the highest mean degrees were attributed to academic-related stressors (ARS), with a mean degree of $2.7 \pm 0.73$, followed by group activity-related stressors (GARS), with a mean degree of $2.1 \pm 0.91$. The mean stress levels for the other four domains ranged between 1.3 \pm 1.25 and $1.9 \pm 0.98$ and were within the range of moderate to high levels. Table 2 also shows that the Cronbach's alpha for the overall questionnaire, intrapersonal- and interpersonalrelated stressors, and academic-related stressors were 0.885 , 0.860 , and 0.753 , respectively, showing high internal consistency. The Cronbach's alpha coefficient values for the other four subscales ranged from 0.65 to 0.714 and indicated satisfactory internal consistency. These results showed that 
Table I Characteristics Variables of the Respondents

\begin{tabular}{|l|l|l|}
\hline Variable & No. & $\%$ \\
\hline Age & & \\
19 & 51 & 19.6 \\
20 & 94 & 36.2 \\
21 & 74 & 28.5 \\
22 & 41 & 15.8 \\
Total & 260 & 100 \\
\hline Year of Study & & \\
Second year & 78 & 30.0 \\
Third year & 99 & 38.1 \\
Fourth year & 83 & 31.9 \\
Total & 260 & 100 \\
\hline Department & & \\
Public Health & 22 & 8.5 \\
Respiratory Care & 64 & 24.6 \\
Physical Therapy & 56 & 21.5 \\
Cardiac Technology & 57 & 21.9 \\
Clinical Nutrition & 31 & 11.9 \\
Health Information Management & 30 & 11.5 \\
Total & 260 & 100 \\
\hline Overall Stress Level & 260 & \\
No to mild stress & 11 & \\
Moderate stress & 108 & 4.7 \\
High stress & 21.5 \\
Severe stress & 260 & 42.7 \\
Total & & 100 \\
\hline Academic Performance (GPA) & \\
Excellent & & \\
Very good & & \\
Good & & \\
Average & & \\
Total & & \\
\hline
\end{tabular}

the MSSQ is a reliable instrument for identifying sources of stress among health profession students.

Table 3 shows that there were significant differences in the levels of stress among health profession students based on year of study. Fourth-year students scored significantly higher in the overall domains and in the academic-related stressors (ARS), group activity-related stressors (GARS), and teaching and learning stressors (TLRS) domains compared with students in other years of study.

A binary logistic regression was performed to assess the association between level of stress and students' academic performance, year of study, and age (Table 4). The model showed a positive association between years of study and stress. The adjusted binary regression revealed that students in their second and third years were significantly less likely to report higher levels of stress compared to fourth-year students $(\mathrm{OR}=0.3 ; 95 \% \mathrm{CI}$ : $0.1-0.8 ; p \leq 0.030$ and $\mathrm{OR}=0.4 ; 95 \% \mathrm{CI}: 0.1-0.5$; $p \leq 0.001$, respectively). Further, academic performance and age were found to be insignificantly associated with stress among the students.

Table 5 reports the rank of each stressor according to the degree of stress perceived by the health profession students. The nine highest mean degrees of stress perceived by the students were considered to be the main factors contributing to the students' stress levels (Table 5). The greatest mean degree of stress was a "lack of time to review what has been learned", with a mean degree of stress of $3.01 \pm 0.98$, which is considered a severe stress level. This was followed by "large amount of content to be learned" (mean $=2.99 \pm 0.93)$, which is close to a severe stress level, "heavy workload" (mean= 2.89 \pm 1.07 ), "tests/ examinations" $($ mean $=2.78 \pm 1.04)$, "need to do well (imposed by others)" (mean= 2.27 \pm 1.19$)$, "facing illness or death of patients" (mean=2.13 \pm 1.45$)$, "participation in class presentation" (mean=2.07 \pm 1.22 ), "feeling of incompetence" (mean=2.04 \pm 1.25$)$, and "uncertainty of what is expected of me" (mean= $2.03 \pm 1.27)$. Four of the nine highest stressors were related to the academic-related stressor (ARS) domain, while three of the nine highest stressors were related to the group activity-related stressors (GARS) domain.

\section{Discussion}

This study explored the levels and main sources of stress as perceived by health profession students and the association between students' stress levels and academic performance. The results showed that $50.8 \%$ of the students were experiencing high stress levels, which is comparable to findings from other studies conducted in Saudi Arabia. ${ }^{12,20,21}$ This may have been due to higher academic demands and the time constraints imposed on the students.

The results indicate that the health profession students perceived the ARS and GARS as leading to the highest stress levels. Meanwhile, the social, intrapersonal and interpersonal, drive and desire, and teaching and learningrelated stressors were perceived as generating moderate stress. It seems that the major source of stress faced by this group of students was related to academic requirements, which were denoted by the ARS and GARS domains. Our findings revealed that academic activities were the key stressors encountered by the health profession students, followed by group activities and teaching 
Table 2 The Mean Domain Scores and Reliability Coefficient Values ( $N=260)$

\begin{tabular}{|l|l|l|l|}
\hline Stressor Domain & $\begin{array}{l}\text { Degree of Stress } \\
\text { Mean (SD) }\end{array}$ & Number of Items & $\begin{array}{l}\text { Cronbach's Alpha } \\
\text { Reliability Coefficients }\end{array}$ \\
\hline Academic-Related Stressors (ARS) & $2.71(0.73)$ & 5 & 0.753 \\
Group Activity-Related Stressors (GARS) & $2.12(0.91)$ & 3 & 0.651 \\
Teaching- and Learning-Related Stressors (TLRS) & $1.95(0.98)$ & 3 & 0.681 \\
Intrapersonal- and Interpersonal-Related Stressors (IRS) & $1.69(1.10)$ & 4 & 0.860 \\
Social-Related Stressors (SRS) & $1.63(1.03)$ & 3 & 0.714 \\
Drive- and Desire-Related Stressors (DRS) & $1.36(1.25)$ & 2 & 0.703 \\
Overall & $2.01(0.69)$ & 20 & 0.885 \\
\hline
\end{tabular}

Abbreviation: SD, standard deviation.

Table 3 One-Way ANOVA of Domain Stress Scores by Year of Study

\begin{tabular}{|c|c|c|c|c|}
\hline Stressor Domains & $\begin{array}{l}\text { Second Year } \\
\text { Mean (SD) }\end{array}$ & $\begin{array}{l}\text { Third Year } \\
\text { Mean (SD) }\end{array}$ & $\begin{array}{l}\text { Fourth Year } \\
\text { Mean (SD) }\end{array}$ & P-value \\
\hline Academic-Related Stressors (ARS) & $2.62(0.67)$ & $2.60(0.79)$ & $2.93(0.67)$ & $0.004 *$ \\
\hline Group Activity-Related Stressors (GARS) & $2.02(0.86)$ & $1.99(0.95)$ & $2.36(0.88)$ & $0.012 *$ \\
\hline Teaching- and Learning-Related Stressors (TLRS) & $1.86(0.86)$ & I.7I ( 1.97$)$ & $2.33(1.00)$ & $0.001 *$ \\
\hline Social-Related Stressors (SRS) & $1.70(0.93)$ & $1.45(1.01)$ & $1.77(1.13)$ & 0.08 \\
\hline Intrapersonal- and Interpersonal-Related Stressors (IRS) & $\mathrm{I} .67(\mathrm{I} .0)$ & $1.52(1.11)$ & $1.91(1.15)$ & 0.057 \\
\hline Drive- and Desire-Related Stressors (DRS) & $1.37(1.23)$ & $1.16(1.21)$ & $1.60(1.29)$ & 0.06 \\
\hline Overall Mean of Stressors & $1.96(0.60)$ & $\mathrm{I} .84(\mathrm{I} .7 \mathrm{I})$ & $2.25(0.69)$ & $0.001 *$ \\
\hline
\end{tabular}

Note: *Significant at $\alpha<0.05$ (2-tailed).

Abbreviation: SD, standard deviation.

and learning. Likewise, a study conducted by Patil et $\mathrm{al}^{25}$ reported that the highest three stressors in descending order of incidence were academic, group activity, and teaching and learning related. A study conducted by

Table 4 Binary Logistic Regression Analysis of the Association Between Stress Among Health Profession Students with Regard to Their Age, Year of Study and Academic Performance

\begin{tabular}{|l|l|l|}
\hline Variables & AOR [95\% C.I.] & P-value \\
\hline Age & & \\
19 (ref) & - & - \\
20 years & $0.6[0.2-1.4]$ & 0.28 \\
21 years & $0.3[0.1-1.7]$ & 0.91 \\
22 years & $0.5[0.1-2.1]$ & 0.36 \\
\hline Year of study & & \\
$4^{\text {th }}$ year (ref) & - & - \\
$3^{\text {rd }}$ year & $0.4[0.1-0.5]$ & $0.001 *$ \\
$2^{\text {nd }}$ year & $0.3[0.1-0.8]$ & $0.030^{*}$ \\
\hline Academic performance & & \\
Below average (ref) & - & - \\
Average & $1.0[0.2-5.1]$ & 0.99 \\
Very good & $0.3[0.7-1.3]$ & 0.11 \\
Excellent & $0.3[0.1-1.3]$ & 0.13 \\
\hline
\end{tabular}

Note: *Significant at $\alpha<0.05$ (2-tailed).

Abbreviations: $\mathrm{AOR}$, adjusted odds ratios; $\mathrm{Cl}$, confidence interval.
Mehta et $\mathrm{al}^{26}$ also reported that the major stressors faced by medical students were academic and group activity related. Additionally, the findings of Habeeb, ${ }^{17}$ Othman et $\mathrm{al},{ }^{27}$ Shelke et $\mathrm{al},{ }^{28}$ Othman et $\mathrm{al},{ }^{29}$ and Muhammad et $\mathrm{al}^{30}$ indicated that ARS was the greatest stressor among the students. One plausible explanation for our results might be the fact that the medical and allied health science disciplines in the study setting are competitive learning environments, which only accept students with the highest grades. Thus, the competitive nature of this environment, in addition to the university's academic workload requirement (eg, the large amount of content to be learned, test/ examination, and lack of time to review what has been learned), might play a significant role in creating stress in our health profession students. Our finding that the students considered a heavy academic workload to be a stressor is consistent with the findings of Sani et $\mathrm{al}^{31}$ and Labrague et $\mathrm{al}^{32}$ who found that Saudi medical and nursing students suffered from high stress levels, mainly due to heavy academic workloads, long hours of study, examinations, and very tight time schedules. The literature has highlighted that extreme experiences of stress can lead to mental and physical problems. ${ }^{33}$ Therefore, it is vital to identify students with early stages of stress to prevent the 
Table 5 Top Stressors Ranked by Mean Degree of Stress as Perceived by Health Profession Students

\begin{tabular}{|l|l|l|}
\hline Statement & Degree of Stress Mean (SD) & Stressor Domain \\
\hline $\begin{array}{l}\text { Causing High to Severe Stress } \\
\text { Lack of time to review what has been learned }\end{array}$ & $3.01(.980)$ & Academic-Related Stressors (ARS) \\
\hline Causing Moderate to High Stress & & \\
Large amount of content to be learned & $2.99(.934)$ & Academic-Related Stressors (ARS) \\
Heavy workload & $2.89(1.078)$ & Academic-Related Stressors (ARS) \\
Tests/examinations & $2.78(1.044)$ & Academic-Related Stressors (ARS) \\
Need to do well (imposed by others) & $2.27(1.191)$ & Group Activity-Related Stressors (GARS) \\
Facing illness or death of patients & $2.13(1.457)$ & Social-Related Stressors (SRS) \\
Participation in class presentation & $2.07(1.224)$ & Group Activity-Related Stressors (GARS) \\
Feeling of incompetence & $2.04(1.258)$ & Group Activity-Related Stressors (GARS) \\
Uncertainty about what is expected of me & $2.03(1.274)$ & Teaching and Learning Stressors (TLRS) \\
\hline Causing Mild to Moderate Stress & $1.94(1.265)$ & Teaching and Learning Stressors (TLRS) \\
Lack of recognition for work done & $1.91(1.164)$ & Academic-Related Stressors (ARS) \\
Falling behind in reading schedule & $1.89(1.352)$ & Intrapersonal and Interpersonal Related Stressors (IRS) \\
Conflict with teacher(s) & $1.89(1.242)$ & Teaching and Learning Stressors (TLRS) \\
Not enough feedback from teacher(s) & $1.83(1.328)$ & Intrapersonal and Interpersonal Related Stressors (IRS) \\
Verbal or physical abuse by teacher(s) & $1.67(1.320)$ & Intrapersonal and Interpersonal Related Stressors (IRS) \\
Verbal or physical abuse by personnel & $1.57(1.245)$ & Social-Related Stressors (SRS) \\
Unable to answer questions from patients &
\end{tabular}

Notes: Degree of stress: $0-1$ is "causing nil to mild stress", I.0I-2.00 is "causing mild to moderate stress", $2.01-3.00$ is "causing moderate to high stress", $3.01-4.00$ is "causing high to severe stress".

Abbreviation: SD, standard deviation.

adverse effects of stress. It is also vital to equip students with adequate coping strategies to overcome such stress, as the literature has shown that students who are able to employ positive coping strategies have less perceived stress. $^{5}$

In the present study, there were significant differences in stress levels based on the year of study. The highest stress levels were observed among fourth-year students in the overall domains and in the ARS, GARS, and TLRS domains when compared with students in other study years. This finding contradicts those of Rahim et al, ${ }^{34}$ who reported that there was no significant difference in stress levels based on the year of study.

In the current study, the logistic regression indicated that the main factor associated with the stress levels of health profession students was the year of study. This finding is in agreement with the findings of other studies, ${ }^{15,35,36}$ showing that the best predictor of student stress levels was the year of study, and the prevalence of stress increased as the year of study increased. Moreover, stress levels were not found to be significantly related with students' age and academic performance, however; this finding is in line with other studies. ${ }^{12,37,38}$
The absence of a significant association between stress levels and academic performance in our study contradicts the findings of Sohail ${ }^{39}$ and Fawzy and Hamed, ${ }^{18}$ who showed that female medical students who had lower academic achievement tended to have higher stress scores than those with higher academic achievement.

As the study findings indicated a high prevalence of stress among female health profession students in their preclinical years, we recommend identifying stressed students and training them appropriately to help them avoid stress burnout. This in turn might help them to adopt stress management strategies that the university could implement and to cope with stress effectively in the later clinical years of their study.

There are some potential limitations to the present study that should be acknowledged. First, since our study was limited to female students from a single university in the KSA, our findings cannot be generalized. Second, information was collected through a self-administered questionnaire; therefore, under- and over reporting is possible. Third, the cross-sectional design of the current study cannot explain the causation of the relationships between variables. Fourth, many sociodemographic variables were not investigated in this study, such as the students' marital status, family 
background, and economic status, which might have an impact on stress levels in university students.

\section{Ethics Approval}

Approval from the Institutional Review Board (IRB) at Imam Abdulrahman Bin Faisal University in the KSA was obtained for the study.

\section{Acknowledgments}

We would like to express our appreciation to all students for their valuable participation in the study.

\section{Disclosure}

The authors report no funding and no conflicts of interest for this work.

\section{References}

1. Myers DG. Stress and health. In: Exploring Psychology. 6th ed. New York: Worth Publishers; 2005:402.

2. Lazarus RS. Theory-based stress measurement. Psychol Inq. 1990;1 (1):3-13. doi:10.1207/s15327965pli0101_1

3. Yusoff MSB, Rahim AFA. The Medical Student Stressor Questionnaire (MSSQ) Manual. Malaysia: KKMED Publications; 2010.

4. Sarkar D, Saha J. Assessment of stress among first year medical students of Chhattisgarh. IOSR J Dental Med Sci. 2015;14:37-40.

5. Guruprakash KV, Mehta SG, Atul B, et al. A study of relationship between perceived stress, coping pattern, burnout, and general psychopathology among the postgraduate medical students. Ind Psychiatr J. 2018;27(1):141-146. doi:10.4103/ipj.ipj_20_18

6. Ganesan Y, Talwar P, Norsiah F, Oon YB. A study on stress level and coping strategies among undergraduate students. J Cognit Sci Human Dev. 2018;3(2):37-47. doi:10.33736/jcshd.787.2018

7. Yusoff MS, Rahim AFA, Baba AA, Ismail SB, Pa MNM, Esa AR. The impact of medical education on psychological health of students: a cohort study. Psychol Health Med. 2013;18(4):420-430. doi:10.1080/13548506.2012.740162

8. Linn BS, Zeppa R. Stress in junior medical students: relationship to personality and performance. J Med Educ. 1984;59(1):7-12.

9. Yusoff MSB, Rahim AFA, Yaacob MJ. The development and validity of the medical student stressor questionnaire (MSSQ). ASEAN J Psychiatr. 2010;11:231-235.

10. Bickel J. Gender equity in undergraduate medical education: a status report. J Womens Health Gend Based Med. 2001;10(3):261-270. doi:10.1089/152460901300140013

11. Houkes I, Winants Y, Twellaar M, Verdonk P. Development of burnout over time and the causal order of the three dimensions of burnout among male and female GPs. A three wave panel study. BMC Public Health. 2011;11(1):240. doi:10.1186/1471-2458-11-240

12. Abdulghani HM, AlKanhal AA, Mahmoud ES, Ponnamperuma GG, Alfaris EA. Stress and its effects on medical students: a cross-sectional study at a college of medicine in Saudi Arabia. $J$ Health Popul Nutr. 2011;29(5):516-522. doi:10.3329/jhpn. v29i5.8906

13. Fried JM, Vermillion M, Parker NH, Uijtdehaage S. Eradicating medical student mistreatment: a longitudinal study of one institution's efforts. Acad Med. 2012;87(9):1191-1198. doi:10.1097/ACM.0b013e 3182625408
14. Amr M, Amin TT, Saddichha S, et al. Depression and anxiety among Saudi university students: prevalence and correlates. Arab J Psychiatr. 2013;24(1):1-7. doi:10.12816/0000092

15. Alalwani BM, Al Juhani A, Fallatah SM, et al. The prevalence of stress among medical students and its effects on academic performance in the Kingdom of Saudi Arabia. Egypt J Hosp Med. 2018;71 (5):3200-3205.

16. Verdonk P, Räntzsch V, de Vries R, et al. Show what you know and deal with stress yourself: a qualitative interview study of medical interns' perceptions of stress and gender. BMC Med Educ. 2014;14 (1):96. doi:10.1186/1472-6920-14-96

17. Habeeb KA. Prevalence of stressors among female medical students Taibah University. $J$ Taibah Univ Sci. 2010;5(2):110-119. doi:10.1016/S1658-3612(10)70140-2

18. Fawzy M, Hamed SA. Prevalence of psychological stress, depression and anxiety among medical students in Egypt. Psychiatr Res. 2017;255:186-194. doi:10.1016/j.psychres.2017.05.027

19. Waqas A, Khan S, Sharif W, Khalid U, Ali A. Association of academic stress with sleeping difficulties in medical students of a Pakistani medical school: a cross sectional survey. PeerJ. 2015;3 (3):e840. doi:10.7717/peerj. 840

20. Abdel Rahman AG, Al Hashim BN, Al Hiji NK, Al-Abbad Z. Stress among medical Saudi students at college of medicine, King Faisal University. J Prev Med Hyg. 2013;54(4):195-199.

21. Al Sunni A, Latif R. Perceived stress among medical students in preclinical years: a Saudi Arabian perspective. Saudi J Health Sci. 2014;3(3):155-159. doi:10.4103/2278-0521.142324

22. Almojali AI, Almalki SA, Alothman AS, Masuadi EM, Alaqeel MK. The prevalence and association of stress with sleep quality among medical students. J Epidemiol Glob Health. 2017;7(3):169-174. doi:10.1016/j.jegh.2017.04.005

23. Yusoff MSB. A confirmatory factor analysis study on the medical student stressor questionnaire among Malaysian medical students. Educ Med J. 2011;3(1):e44-53. doi:10.5959/eimj.v3i1.95

24. Streiner LD, Norman GR. Health Measurement Scales: A Practical Guide to Their Development and Use. 4th ed. New York: Oxford University Press; 2008.

25. Patil SP, Sadhanala S, Srivastav MU, BansodeGokhe SS. Study of stressors among undergraduate medical students of a teaching medical institution. Int $J$ Commun Med Public Health. 2017;4 (9):3151-3154. doi:10.18203/2394-6040.ijcmph20173655

26. Mehta P, Thekdi K, Rokad M, Patel K, Bhadu A, Sorani P. Exploratory study to access anxiety, depression and stress among medical students, freshly starting their medical education in a medical college. Sch J App Med Sci. 2013;1:819-822.

27. Othman CN, Farooqui M, Yusoff MSB, Adawiyah R. Stress coping level among health science students in a Malaysian university. J ASIAN Behav Stud. 2018;3(9):131-139. doi:10.21834/jabs.v4i17.80

28. Shelke US, Kunkulol RR, Narwane SP. Level of stress in final year MBBS students at rural medical college: a cross-sectional study. Int J Med Res Health Sci. 2014;3(4):886-891. doi:10.5958/23195886.2014.00020.4

29. Othman CN, Farooqui M, Yusoff MSB, Adawiyah R. Nature of stress among health science students in a Malaysian university. Procedia Soc Behav Sci. 2013;105:249-257. doi:10.1016/j.sbspro.2013.11.026

30. Muhammad DG, Ahmad AA, Usman JS. Assessment of level and sources of stress among allied health sciences students of Bayero University Kano: a comparison between clinical and pre-clinical students. Educ Med J. 2019;11(1):11-19. doi:10.21315/eimj2019.11.1.2

31. Sani M, Mahfouz M, Bani I, Alsomily AH, Alagi D, Alsomily NY. Prevalence of stress among medical students in Jizan University, Kingdom of Saudi Arabia. Gulf Med J. 2012;1(1):19-25.

32. Labrague LJ, McEnroe-Petitte DM, De Los Santos JAA, Edet OB. Examining stress perceptions and coping strategies among Saudi nursing students: a systematic review. Nurse Educ Today. 2018;65:192-200. doi:10.1016/j.nedt.2018.03.012 
33. Niemi PM, Vainiomäki PT. Medical students' academic distress, coping, and achievement strategies during the preclinical years. Teach Learn Med. 1999;11(3):125-134. doi:10.1207/S15328015TL110302

34. Rahim MSA, Saat NZM, Siti-Aishah H, et al. Relationship between academic workload and stress level among biomedical science students in Kuala Lumpur. $J$ Appl Sci. 2016;16(3):108-112. doi:10.3923/jas.2016.108.112

35. Yusoff MS, Rahim AFA, Yaacob MJ. Prevalence and sources of stress among University Sains Malaysian medical students. Malays J Med Sci. 2010;17(1):30-37.

36. Anuradha R, Dutta R, Raja JD, Sivaprakasam P, Patil AB. Stress and stressors among medical undergraduate students: a cross-sectional study in a private medical college in Tamil Nadu. Indian J Community Med. 2017;42(4):222-225. doi:10.4103/ijcm.IJCM_287_16
37. Shah M, Hasan S, Malik S, Sreeramareddy CT. Perceived stress, sources and severity of stress among medical undergraduates in a Pakistani medical school. BMC Med Educ. 2010;10(1):2. doi:10.1186/1472-6920-10-2

38. Bexelius T, Lachmann $H$, Järnbert-Pettersson $H$, Kalén $S$, Möller R, Ponzer S. Stress among medical students during clinical courses: a longitudinal study using contextual activity sampling system. Int J Med Educ. 2019;10:68-74. doi:10.5116/ ijme. 5 c 94.9391

39. Sohail N. Stress and academic performance among medical students. J Coll Physicians Surg Pak. 2013;23(1):67-71.

\section{Publish your work in this journal}

The Journal of Multidisciplinary Healthcare is an international, peerreviewed open-access journal that aims to represent and publish research in healthcare areas delivered by practitioners of different disciplines. This includes studies and reviews conducted by multidisciplinary teams as well as research which evaluates the results or conduct of such teams or healthcare processes in general. The journal covers a very wide range of areas and welcomes submissions from practitioners at all levels, from all over the world. The manuscript management system is completely online and includes a very quick and fair peer-review system. Visit http://www.dovepress.com/testimonials. php to read real quotes from published authors. 